 \\ Evaluation of applicants' satisfaction index in engineering courses in Portugal during pre- and Post-Bologna period
}

Cite as: AIP Conference Proceedings 2293, 420105 (2020); https://doi.org/10.1063/5.0026840 Published Online: 25 November 2020

Raquel Oliveira, A. Manuela Gonçalves, and Rosa M. Vasconcelos

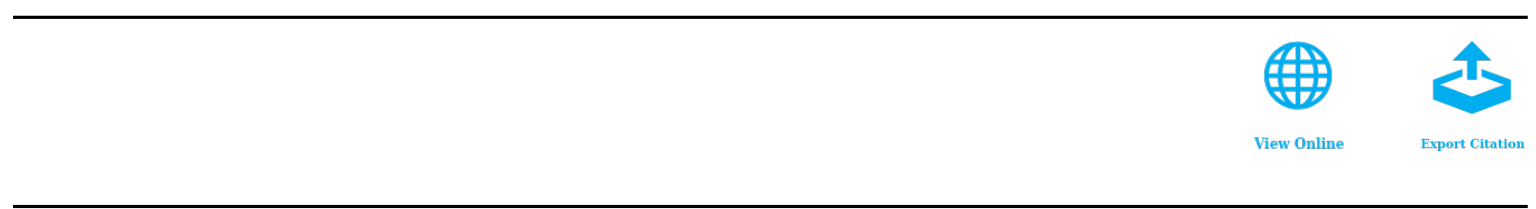

Challenge us.

What are your needs for periodic signal detection?

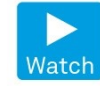

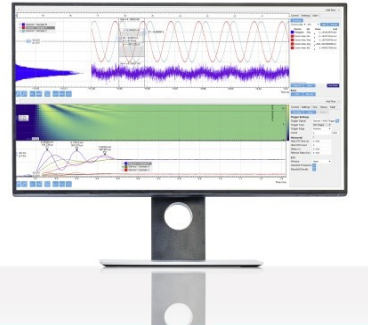

Zurich

Instruments 


\title{
Evaluation of Applicants' Satisfaction Index in Engineering Courses in Portugal during Pre- and Post-Bologna Period
}

\author{
Raquel Oliveira ${ }^{1, \text { a) }}$, A. Manuela Gonçalves ${ }^{2, \text { b) }}$ and Rosa M. Vasconcelos ${ }^{3, c)}$ \\ ${ }^{1}$ University of Minho, CMAT-Centre of Mathematics, Portugal, IPCA_EST, Barcelos, Portugal \\ ${ }^{2}$ University of Minho, CMAT-Centre of Mathematics, DMA-Department of Mathematics and Applications, \\ Portugal \\ ${ }^{3}$ University of Minho,2C2T - Centre for Textile Science and Technology, DET-Department of Textile Engineering, \\ Portugal \\ a)rmro_17@hotmail.com \\ b) mneves@math.uminho.pt \\ c)rosa@det.uminho.pt
}

\begin{abstract}
In this work we describe and characterize students' allocation satisfaction in the Portuguese public higher education system, through the students' own point of view, namely in academic engineering programs, extending previous studies by the author's team. We compare the ratio provided by the Portuguese Ministry of Education with the institutions' point of view, the demand satisfaction index with the ratio proposed, and the applicants' satisfaction index for the Pre- and Post-Bologna period. The dataset used in this paper was provided by the Portuguese Education Institute and covers the results of the national contest from 1997 to 2015 . Non-parametric tests were performed in order to assess whether there are significant differences between the ratios and to allow a better understanding of the applicants' satisfaction index in engineering courses during Pre- and Post-Bologna period.
\end{abstract}

\section{INTRODUCTION}

Portugal has a binary higher education system, consisting of university and polytechnic education, each with distinct purposes that translate into specific curricular concepts, [1].

University education, guided by a constant perspective of promoting research and knowledge creation, aims at ensuring a solid scientific and cultural preparation by providing a technical training that qualifies students for the exercise of professional and cultural activities and by promoting the development of design capabilities, innovation and critical analysis. Polytechnic education, guided by a constant perspective of applied research and development, aims at understanding and solving specific problems, at providing a solid cultural and technical level, and at developing the capacity for innovation, critical analysis and its applications in the pursuit of professional activities.

University education is offered by public and private university institutions, while polytechnic education is offered by public and private non-university institutions. Private higher education institutions must be subject to the previous recognition of the Ministry of Education and Science (the higher education system also comprises a concordatary institution) [1]. Both university and polytechnic institutions confer the degree of licenciado (bachelor). In polytechnic education, the cycle of studies leading to the degree of licenciado has a duration of 3 years of students' work and 180 credits.

In certain cases, namely those covered by internal legislation or by European legislation, the cycle of studies can have up to 240 credits with a normal length of up to seven or eight curricular semesters of students' work. In university education, the cycle of studies that leads to the degree of licenciado has from 180 to 240 credits and a normal length of six to eight curricular semesters of students' work. 
Both university and polytechnic institutions confer the degree of mestre (master). The cycle of studies leading to the degree of mestre has from 90 to 120 credits and a normal length of three to four curricular semesters of students' work or, in exceptional circumstances, 60 credits and a duration of two semesters, resulting from a stable and consolidated practice in that specific field at international level.

In university education, the degree of mestre may also be conferred after an integrated cycle of studies (integrated master), with 300 to 360 credits and a normal length of 10 to 12 curricular semesters of students' work, for cases in which access to the practice of a certain professional activity depends on that length of time established by legal European Union (EU) standards or resulting from a stable practice consolidated in the EU. In this cycle of studies, the degree of licenciado is conferred to those who have obtained 180 credits, corresponding to the first six semesters of work. The degree of doutor (doctor) is conferred by universities and university institutes.

This study focuses on the publicly-funded higher education system that offers engineering study programs of bachelor or integrated master, since these programs include the majority of candidates; they are also representative in terms of supply of land area and their access is regulated by the Department of Higher Education (Direção Geral do Ensino Superior - DGES). The implementation of the Bologna Process in Portugal was led by the Portuguese Ministry of Science, Technology and Higher Education (MSTHE), and it was a part of a process of reorganization and rationalization of the higher education system [1].

\section{STATISTICAL ANALYSIS}

The used data is available online on a DGES website [2] designed to disseminate the results of the applicants' allocation in the national competition. The variables used were also the same considered in work [3], and [4]: number of students who have selected each program as their first choice; number of vacancies available for each program in the first stage of the application process; number of applicants allocated in their first choice; demand satisfaction index (ratio between the number of candidates placed on their first option and the number of places available in each study program); applicants' satisfaction index (ratio between the number of candidates on their first option and the total number of candidates in their first option for each study program) [3]. The dataset comprises the Higher Education Institutions (HEI) in the public education sector. These HEI offer the number of available engineering study programs.

Due to differences in higher education access, most of the data available is related to the public sector disseminated by the DGES according to the results of the different phases of the national contest. So, this study focuses on the publicly-funded higher education system that offers engineering study programs of bachelor or integrated master, since these programs include the majority of the candidates and they are also representative in terms of supply of land area and their access is regulated by the DGES. The data was collected for the period between 1997 and 2015, regarding the first phase: Pre-Bologna (1997-2006) and Post-Bologna (2007-2015). Statistical analysis was performed using the SPSS statistic software and STATA statistical data analysis software.

The number of IHE in both periods is similar: a minimum of 26 IHE and a maximum 0f 30 IHE, but this similarity is not present in its variation for it has an opposite variation. Fig. 1 and Fig. 2 represent, respectively, the total of applicants and the total of allocated candidates for the national contest also by period.

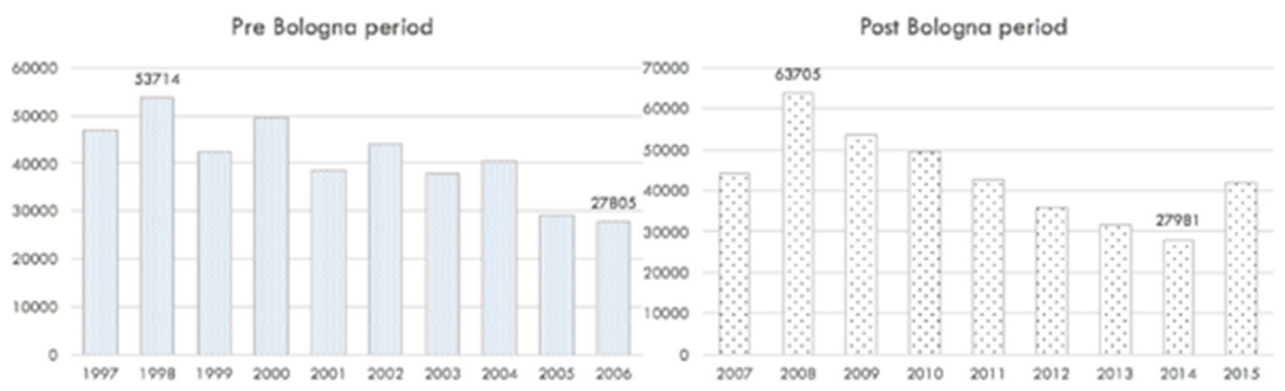

FIGURE 1. Total number of applicants. 


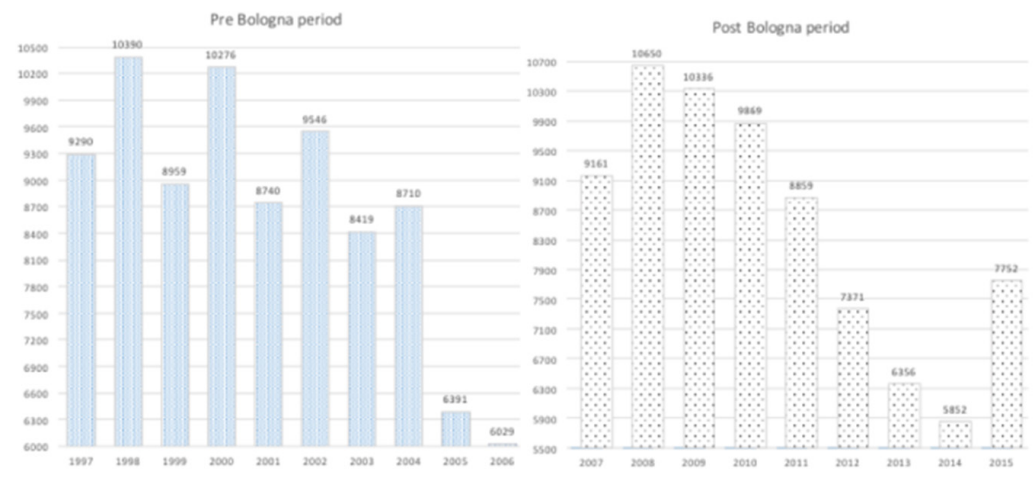

FIGURE 2. Total number of allocated candidates.

Despite the higher number of applicants in the Post Bologna period (2008), generally the number of applicants has decreased over the years. In relation to the allocated candidates, the maximum and minimum values have been achieved in the post-Bologna period, and the most extreme variations occurred at the end of the two periods under observation. Fig. 3 and Fig. 4 illustrate, respectively, the number of total applicants and the number of engineering academic programs by IHE type.
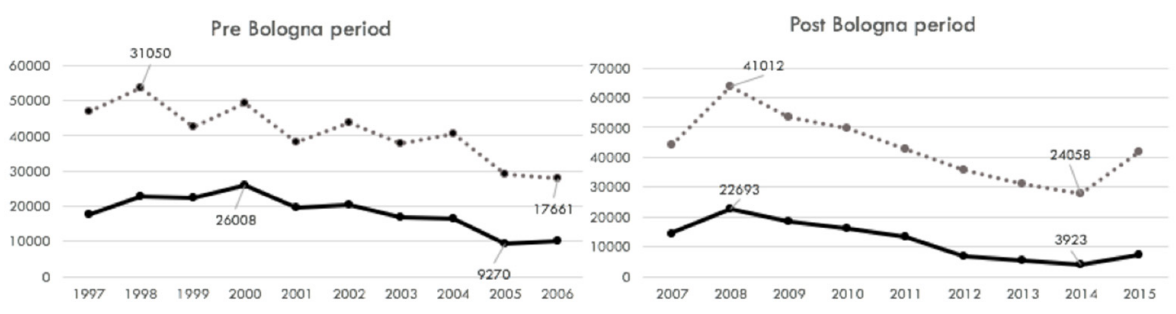

FIGURE 3. Total number of applicants by IHE type.
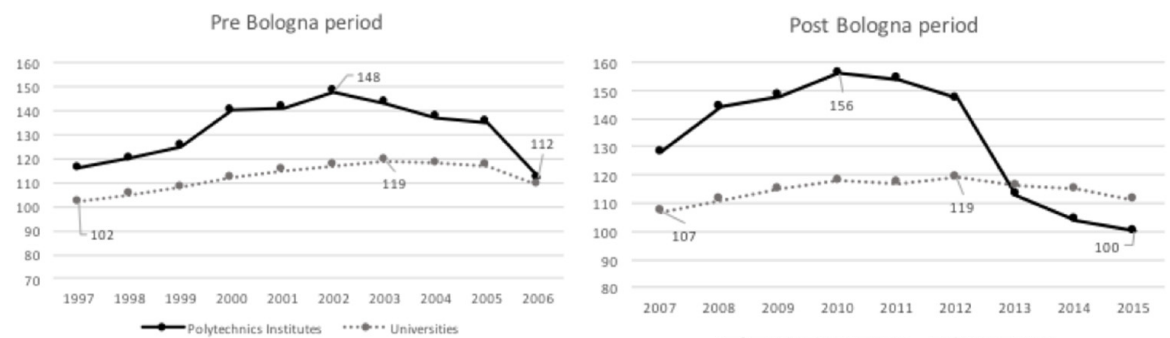

FIGURE 4. Number of Engineering programs by HEI type.

A Kolmogorov-Smirnov test was used to verify data normality (p-value $<0.001$ ), and the results indicated that non-parametric tests should be used for all comparisons. In order to analyze whether the number of applicants to Engineering programs (demand) depends on the type of institution or degree (size of program), some tests were performed (Table 1), [5] and [6].

The demand (number of applicants) for Engineering programs depended on the size of the programs for the two periods, but if we only consider the type of IHE then there is no dependency during the pre-Bologna period, from 1999 to 2002.

We verified that the differences between the two indices have been maintained in recent years, which leads us to believe that the proposed index becomes relevant as an element to be taken into account in the analysis of the issues surrounding the satisfaction of applicants in accessing higher education, thus introducing a dimension of analysis that 
considers the candidates' own point of view. This analysis will be the subject of future work focused on conducting the comparison between the two periods in order to assess the impact of the Bologna Process on student allocation in academic Engineering programs in Portugal.

TABLE 1. Mann-Whitney and Kruskal-Wallis tests for the pre- and post-Bologna period.

\begin{tabular}{|c|c|c|c|c|c|c|}
\hline & & Mann-Whitney & Kruskal-Wallis & & Mann-Whitney & Kruskal-Wallis \\
\hline & Pre-Bologna & IHE type & Size of program & Post-Bologna & IHE type & Size of program \\
\hline Test statistics & 1997 & -4.068 & 16.552 & 2007 & -6.438 & -7.324 \\
\hline p-value & & $<0.0001$ & $<0.0001$ & & $<0.0001$ & $<0.0001$ \\
\hline Test statistics & 1998 & -3.245 & 20.686 & 2008 & -7.287 & -7.493 \\
\hline p-value & & 0.001 & $<0.0001$ & & $<0.0001$ & $<0.0001$ \\
\hline Test statistics & 1999 & -0.165 & 15.939 & 2009 & -7.990 & -8.367 \\
\hline p-value & & 0.869 & $<0.0001$ & & $<0.0001$ & $<0.0001$ \\
\hline Test statistics & 2000 & -0.346 & 11.503 & 2010 & -8.761 & -8.914 \\
\hline p-value & & 0.729 & 0.003 & & $<0.0001$ & $<0.0001$ \\
\hline Test statistics & 2001 & -0.331 & 7.746 & 2011 & -9.143 & -9.014 \\
\hline p-value & & 0.741 & 0.021 & & $<0.0001$ & $<0.0001$ \\
\hline Test statistics & 2002 & -1.397 & 8.095 & 2012 & -10.352 & -9.023 \\
\hline p-value & & 0.162 & 0.017 & & $<0.0001$ & $<0.0001$ \\
\hline Test statistics & 2003 & -2.229 & 10.310 & 2013 & -8.897 & -8.240 \\
\hline p-value & & 0.026 & 0.006 & & $<0.0001$ & $<0.0001$ \\
\hline Test statistics & 2004 & -3.190 & 16.367 & 2014 & -8.697 & -7.926 \\
\hline p-value & & 0.001 & $<0.0001$ & & $<0.0001$ & $<0.0001$ \\
\hline Test statistics & 2005 & -5.351 & 33.030 & 2015 & -8.841 & -7.537 \\
\hline p-value & & $<0.0001$ & $<0.0001$ & & $<0.0001$ & $<0.0001$ \\
\hline Test statistics & 2006 & -3.257 & 45.001 & & & \\
\hline p-value & & 0.001 & $<0.0001$ & & & \\
\hline
\end{tabular}

\section{ACKNOWLEDGMENTS}

This work is financed by FEDER funds through the Competitivity Factors Operational Programme - COMPETE and by national funds through FCT - Foundation for Science and Technology within the scope of the project POCI01-0145-FEDER-007136 and the Project PEstOE/MAT/ UI0013/2017.

\section{REFERENCES}

1. OECD, Organization for economic co-operation and Development (2006). Reviews of National policies for education: Tertiary education in Portugal. Examiner's Report. Available at http://www.dges.mctes.pt/NR/rdonlyres/8B016D34-DAAB-4B50-ADBB-

25AE105AEE88/2564/Backgoundreport.pdf.

2. http://www. dges.mctes.pt/DGES/pt/Estudantes/Acesso.

3. R. Oliveira, A. M. Gonçalves and Rosa M. Vasconcelos, "A New Perspective of Students Allocation Satisfaction in Engineering Courses in Portugal” AIP Conference Proceedings 41648, 840002 (2015); doi:10.1063/1.4913042.

4. R. Oliveira, A. M. Gonçalves and Rosa M. Vasconcelos, "Index of satisfaction in engineering courses in Portugal based on the student's perspective" AIP Conference Proceedings 1738, 840002, 470003 (2016); doi: 10.1063/1.4952233.

5. J.H. Higgins, "Introduction to Modern Nonparametric Statistics". Thomson, Toronto, 2004.

6. S. Siegel and N.J. Castellan, "Nonparametric Statistics for the Behavioral Sciences". McGraw-Hill, $2^{\text {a }}$ Edition, 1998. 